\title{
SUMMARY OF THE VALIDATION OF THE SECOND VERSION OF THE ASTER GDEM
}

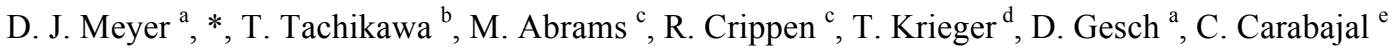 \\ ${ }^{\text {a }}$ US Geological Survey, Earth Resource Observation and Science Center, Sioux Falls, SD, USA - (dmeyer, \\ gesch)@usgs.gov \\ ${ }^{\mathrm{b}}$ Earth Remote Sensing Data Analysis Center, Tokyo, Japan - tatikawa@ersdac.or.jp \\ ${ }^{\mathrm{c} J e t}$ Propulsion Laboratory, California Institute of Technology, Pasadena, CA, USA - (mabrams, \\ robert.e.crippen)@jpl.nasa.gov \\ ${ }^{d}$ US National Geospatial Intelligence Agency, St. Louis, MO, USA - Tabitha.L.Krieger@nga.mil \\ 'Sigma Space Corp, NASA Goddard Space Flight Center, Greenbelt, MD, USA-Claudia.C.Carabajal@nasa.gov
}

\section{Commission VI, WG VI/6}

KEY WORDS: ASTER, Global Digital Elevation Model, Accuracy, DEM/DTM, Comparison, Geodesy, Global-EnvironmentalDatabases, Land Cover, Mapping, Satellite

\begin{abstract}
:
On October 17, 2011, NASA and the Ministry of Economy, Trade and Industry (METI) of Japan released the second version of the Advanced Spaceborne Thermal Emission and Reflection Radiometer (ASTER) Global Digital Elevation Model (GDEM) to users worldwide at no charge as a contribution to the Global Earth Observing System of Systems (GEOSS). The first version of the ASTER GDEM, released on June 29, 2009, was compiled from over 1.2 million scene-based DEMs covering land surfaces between $83^{\circ} \mathrm{N}$ and $83^{\circ} \mathrm{S}$ latitudes. The second version (GDEM2) incorporates 260,000 additional scenes to improve coverage, a smaller correlation kernel to yield higher spatial resolution, and improved water masking.
\end{abstract}

As with GDEM1, US and Japanese partners collaborated to validate GDEM2. Its absolute accuracy was within -0.20 meters on average when compared against 18,000 geodetic control points over the conterminous US (CONUS), with an accuracy of 17 meters at the $95 \%$ confidence level. The Japan study noted the GDEM2 differed from the 10 -meter national elevation grid by -0.7 meters over bare areas, and by 7.4 meters over forested areas. The CONUS study noted a similar result, with the GDEM2 determined to be about 8 meters above the 1 arc-second US National Elevation Database (NED) over most forested areas, and more than a meter below NED over bare areas. A global ICESat study found the GDEM2 to be on average within 3 meters of altimeter-derived control. The Japan study noted a horizontal displacement of 0.23 pixels in GDEM2. A study from the US National Geospatial Intelligence Agency also determined horizontal displacement and vertical accuracy as compared to the 1 arc-second Shuttle Radar Topography Mission DEM. US and Japanese studies estimated the horizontal resolution of the GDEM2 to be between 71 and 82 meters. Finally, the number of voids and artifacts noted in GDEM1 were substantially reduced in GDEM2.

\section{INTRODUCTION}

The ASTER instrument on NASA's Terra spacecraft collects intrack stereo using nadir- and aft looking near infrared cameras. These stereo pairs are used to produce single-scene $(60 \times 60$ $\mathrm{km}$ ) digital elevation models having vertical (root-meansquared-error) accuracies generally between $10 \mathrm{~m}$ and $25 \mathrm{~m}$. On June 29, 2009, NASA and METI released a Global Digital Elevation Model (GDEM) to users worldwide at no charge as a contribution to the Global Earth Observing System of Systems (GEOSS). This "version 1" ASTER GDEM (GDEM1) was compiled from over 1.2 million scene-based DEMs covering land surfaces between $83^{\circ} \mathrm{N}$ and $83^{\circ} \mathrm{S}$ latitudes. GDEM1 is a 1 arc-second elevation grid distributed as $1^{\circ}$-by- $1^{\circ}$ tiles.

A joint US-Japan validation team assessed the accuracy of the GDEM1, augmented by a team of 20 cooperators selected through an Announcement of Opportunity (AO). In summary, the GDEM1 was found to have an overall accuracy of around 20 meters at the $95 \%$ confidence level. The team also noted several artifacts associated with poor stereo coverage at high latitudes, cloud contamination, water masking issues and the stacking process used to produce the GDEM1 from individual scene-based DEMs (ASTER GDEM Validation Team, 2009). Two independent horizontal resolution studies estimated the effective spatial resolution of the GDEM1 to be on the order of 120 meters (Crippen, 2009; Tachikawa et al. 2009).

NASA and METI released a second version of the ASTER GDEM (GDEM2) on October, 17, 2011. The GDEM2 has the same gridding and tile structure as GDEM1, but benefits from the inclusion of 260,000 additional scenes to improve coverage, a smaller correlation kernel (5x5 versus 9x9 for GDEM1) yielding higher spatial resolution, and improved water masking. Also, a negative 5 meter overall bias observed in the GDEM1 was removed in newer version. As with the GDEM1, the GDEM2 validation was the joint responsibility of U.S. and Japanese partners. The U.S. validation team included the U.S. Geological Survey (USGS), NASA's Jet Propulsion Laboratory (JPL), the National Geospatial-Intelligence Agency (NGA) and the NASA Goddard Space Flight Center (GSFC). The Japanese validation was conducted by the Earth Remote Sensing Data

\footnotetext{
* Corresponding author.
} 
Analysis Center (ERSDAC) in cooperation with the University of Tokyo and Mitsubishi Materials Techno Corporation (under contract to ERSDAC). As before, the GDEM2 will be distributed at no charge to users through ERSDAC on behalf of METI, and at the Land Processes Distributed Active Archive Center (LP DAAC), located at the USGS Earth Resource Observation and Science Center (EROS), on behalf of NASA.

\section{METHODS}

\subsection{Japan/ERSDAC validation}

The Japanese validation team's methods for evaluating the GDEM2 is documented in detail by Tachikawa et al. (2011), but is briefly summarized here. The primary reference used for the Japan study is the $10-\mathrm{m}$ mesh DEM produced by the Geographical Survey Institute (GSI) of Japan. The study focused on 4 GDEM2 tiles in central Honshu Island, spanning elevations from sea level to peaks exceeding 3000 meters. The impact of land cover on GDEM2 elevation errors was determined by stratifying the GDEM2 against the GSI's "Subdivision Land Use Data of Digital National Land Information", a 100-m land cover grid derived from satellite, aerial photography and field measurements. This land cover dataset was most recently updated in 2007. The Japan assessment included horizontal and vertical accuracy assessment against the GSI DEM, a horizontal resolution estimate against the GSI DEM decimated to variable resolutions, and an assessment of artifacts.

\subsection{CONUS validation}

The validation over the CONUS by the USGS (Gesch et al., 2011) is described in another paper within this session and will not be treated here, other than comparing results between the various validation efforts. Briefly, the USGS approach estimated absolute vertical accuracy against global positioning system (GPS) measurements on over 18,000 geodetic benchmarks, and compared the GDEM2 against the US National Elevation Database (NED). This study evaluated the influences of land cover, especially "tall" cover such as forests, on the validation results.

\subsection{Global SRTM validation}

The NGA reproduced much of the work done for GDEM1, using the same 284 GDEM tiles as before, located at 20 geographic areas globally (Krieger et al., 2011). The results from the current GDEM2 validation are based on either a comparison with global 1 arc-second Shuttle Radar Topography Mission (SRTM) digital terrain elevation data ("DTED level 2", or "DTED2"), or with the GDEM1. The NGA also did an extensive visual identification of artifacts in the GDEM2.

\subsection{Global ICESat validation}

The NASA Planetary Geodynamics group at the Goddard Space Flight Center (GSFC) evaluated the GDEM2 against data collected by the Geoscience Laser Altimeter System (GLAS) on board the Ice, Cloud and land Elevation satellite (ICESat). The results are described in another paper in this session, and will not be treated here, other than in comparison with other validation studies (Carabajal, 2011).

\subsection{Characterization of horizontal resolution, artifacts.}

The JPL and ERSDAC teams estimated the horizontal resolutions of the GDEMs and other GDEMs, and characterized artifacts in the GDEM2. This study was based on comparisons to higher resolution DEMs derived from LIDAR and nonLIDAR sources.

\section{RESULTS}

In summary, changes in the number of acquired ASTER stereo pairs and improvements in processing (water masking, smaller correlation kernel size, bias removal) have produced significant improvements in GDEM2 as compared to GDEM1. These improvements include increased horizontal and vertical accuracy, as compared to both GPS benchmarks and standard DEMs (GSI, NED, STRM DTED2), and improved horizontal accuracy and resolution (similar to the SRTM DTED2).

The ERSDAC Japan study is summarized in table 1 below:

\begin{tabular}{|c|c|c|c|c|}
\hline & & & GDEM1 & GDEM2 \\
\hline \multicolumn{3}{|c|}{ Horizontal error } & 0.82 “west & 0.13 “west \\
\hline \multirow{6}{*}{$\begin{array}{l}\text { Ver- } \\
\text { tical } \\
\text { error }\end{array}$} & \multirow{3}{*}{$\begin{array}{l}\text { Flat } \\
\text { terrain }\end{array}$} & Offset & $-4.8 m$ & $-0.7 \mathrm{~m}$ \\
\hline & & Std Dev & $6.2 \mathrm{~m}$ & $5.9 \mathrm{~m}$ \\
\hline & & RMSE & -- & $6.1 \mathrm{~m}$ \\
\hline & \multirow{3}{*}{$\begin{array}{l}\text { Forest } \\
\text { terrain }\end{array}$} & Offset & $2.2 \mathrm{~m}$ & $7.4 \mathrm{~m}$ \\
\hline & & Std Dev & $15.4 \mathrm{~m}$ & $12.7 \mathrm{~m}$ \\
\hline & & RSME & -- & $15.1 \mathrm{~m}$ \\
\hline \multicolumn{3}{|c|}{ Horizontal resolution } & $3.8^{\prime \prime}(114 \mathrm{~m})$ & $2.4 "(72 \mathrm{~m})$ \\
\hline
\end{tabular}

Table 1: Results from the ERSDAC study (note: horizontal resolution estimates assume $1 "=30 \mathrm{~m}$ )

This study determined:

- The voids in northern areas have decreased due to new ASTER acquisitions.

- The artifacts are significantly reduced as a result.

- All lakes in the Japan study are rendered flat by the new water body detection algorithm (although inland water body problems exist elsewhere, as determined by JPL).

The US/CONUS validation raised several important observations about the quality of elevation measurements contained in GDEM2, some of which are shown here in comparison to other results:

- The overall RMSE of nearly two-thirds of a meter $(8.68 \mathrm{~m}$ vs. $9.34 \mathrm{~m}$ of GDEM 2 over GDEM1, along with an improvement in overall mean error (bias) in GDEM2 when compared with GDEM1 (-0.20 m vs. $-3.69 \mathrm{~m})$, largely agrees with the ERSDAC study.

- The influence of the GDEM2 by above ground features (tree canopies and built structures) is in agreement with the Japan study that also noted a positive bias over forest cover types.

- The GDEM2 has elevations that are higher in the canopy than SRTM. This observation is based on both the comparison of GDEM2 with GPS benchmarks, as well as the GDEM2-SRTM differencing. Once again, this finding was reinforced in the Japan study, although the latter had a larger bias for tall cover types: 8.68 meters, compared to 3.10 meters for the CONUS study (see Meyer et al. , 2011).

- The improvement in accuracy due in the number of "stacking" scene DEMS used to derive elevation valuse is minimal beyond about 15 scenes, largely in agreement with the ICESat findings. 
- GDEM2 exhibits an apparent "true" negative elevation bias of about 1 meter, which was revealed through an analysis of mean error by land cover type. This is discussed in more detail in the USGS presentation.

The horizontal resolution estimates were similar from the US and Japan teams when using non-LIDAR reference data sets, with GDEM2 estimated at $70 \mathrm{~m}$ and $72 \mathrm{~m}$, respectively, and GDEM1 estimated at 118 and 114, respectively. The US team's additional estimates using LIDAR-derived high-resolution reference data averaged $82 \mathrm{~m}$ for GDEM2 versus $121 \mathrm{~m}$ for GDEM1. These higher estimates were the expected result of using a more precise and accurate reference DEM. The same LIDAR sites also produced average estimates of $77 \mathrm{~m}$ for SRTM 1-arc-second data and $102 \mathrm{~m}$ for SRTM 3-arc-second data. These results are summarized in Table 2 .

\begin{tabular}{|l|r|r|}
\hline DEM & Average Non- LIDAR & Average LIDAR \\
\hline GDEM1 & $116 \mathrm{~m}$ & $121 \mathrm{~m}$ \\
\hline GDEM2 & $71 \mathrm{~m}$ & $82 \mathrm{~m}$ \\
\hline SRTM 1" & $72 \mathrm{~m}$ & $77 \mathrm{~m}$ \\
\hline SRTM 3" & $97 \mathrm{~m}$ & $102 \mathrm{~m}$ \\
\hline
\end{tabular}

Table 2: Comparison of JPL \& ERSDAC horizontal resolution estimates for several GDEMs.

Unfortunately, the addition of higher-frequency topographic signal in GDEM2 as compared to GDEM1 came at the cost of added, nearly ubiquitous, high frequency noise, as is visually apparent and as indicated by the higher standard deviation of differences from benchmark elevations (USGS) and from SRTM postings (NGA) despite the general reduction of artifacts such as pits and spikes. However, noisy signal is generally better than missing signal, and fine noise can be suppressed by filtering if critical, so even from a signal and noise tradeoff perspective we conclude that GDEM2 is more versatile than GDEM1.

While it is fairly clear from NGA's high-level review that the quality of GDEM2 is superior to GDEM1 (especially above 60 degrees north), the data would still have to be assessed and edited on a case-by-case basis before use in specific NGA applications.

The ICESat study concluded that globally (with the exception of Greenland), the GDEM2 elevations are on average within 3 meters of highly edited altimeter measurements, with standard deviations and RMSEs under 12 meters. For bare ground, the GDEM2 was on average within around 2 meters to the altimeter measurements (with the exception of New Zealand), having standard deviations and RSMEs under 12 meters. Although the GDEM2 exhibits large errors over much of Greenland, for those areas classified as either bare or herbaceous, the errors are on average within 2 meters of the ICESat elevations.

\section{REFERENCES}

ASTER GDEM Validation Team, 2009, ASTER Global DEM Validation Summary Report, 28 p.

Carabajal, C.C. (2011) ASTER global DEM version 2.0 evaluation using ICESat geodetic ground control. Report to the ASTER GDEM Version 2 Validation Team.
Crippen, R.E. (2009). Spatial resolution of the ASTER global elevation model (GDEM). Presentation at the $35^{\text {th }}$ ASTER Science Team Meeting, Kyoto, Japan.

Gesch, D., M. Oimoen, Z. Zhang, J. Danielson, D. Meyer (2011). Validation of the ASTER Global Digital Elevation Model (GDEM) Version 2 over the Conterminous United States. Report to the ASTER GDEM Version 2 Validation Team.

Meyer. D, T. Tachikawa, M. Kaku, A. Iwasaki, D. Gesch, M. Oimoen, Z. Zheng, J. Danielson, T. Krieger, W. Curtis, J. Haase, M. Abrams, R. Crippen, C. Carabajal (2011). ASTER Global Digital Elevation Model Version 2 - Summary of Validation Results. Report to the ASTER GDEM Version 2 Validation Team.

Tachikawa, T., M. Kaku, and A. Iwasaki (2009). ASTER GDEM validation. Presentation at the $35^{\text {th }}$ ASTER Science Team Meeting, Kyoto, Japan.

Tachikawa, T., M., Kaku, A. Iwasaki (2011) ASTER GDEM Version 2 Validation Report. Report to the ASTER GDEM Version 2 Validation Team. 